\title{
AN ANALYSIS OF CRITICAL THINKING SKILLS AMONGST BUSINESS STUDENTS IN KUWAIT
}

\author{
James Goodpasture ${ }^{1}$, Mark Speece ${ }^{2}$, Jeremy Cripps $^{3}$ \\ ${ }^{1}$ College of Business Administration, Tarleton State University, USA, goodpasture@tarleton.edu \\ ${ }^{2}$ College of Business and Economics, American University of Kuwait, Kuwait, mspeece@auk.edu.kw \\ ${ }^{3}$ College of Business, The University of Findlay, USA, cripps@findlay.edu
}

\begin{abstract}
Research Purpose. This article examined critical thinking skills amongst senior-level undergraduate students in a Middle East setting, Kuwait. In addition, the study investigated the gender differences.

Methodology. The subjects involved in this study comprised a convenience sample of 90 graduating seniors. The purpose of this study was to assess the impact of two motivational factors on the development of critical thinking skills. The analysis used the specific subsection about critical thinking skills, which is part of the Motivated Strategies for Learning Questionnaire (MSLQ). One factor relates the sense of entitlement that can arise in a welfare state, which heavily subsidises a wide range of things for citizens, including education. We examined differences between citizens and non-citizens, who do not have access to welfare benefits.

Findings. The results supported the hypotheses that student groups have different levels of critical thinking skills. We found that expatriate students had more highly developed critical thinking skills than students who were Kuwaiti citizens. We also found that women had more highly developed critical thinking skills than men had.

Practical Implications. The welfare state measures undertaken by the government of Kuwait may be counterproductive. The guaranteed employment of its citizens and generous monetary support whilst in school may discourage the development of critical thinking skills. Future research could focus on ways to motivate particular groups (e.g. Kuwaiti men) to enhance their critical thinking skills.
\end{abstract}

Keywords: Critical Thinking; MSLQ; Kuwait; Gender; Welfare State; Cultural Economics.

JEL codes: I28

\section{Introduction}

Critical thinking is the ability to apply previous knowledge in order to solve problem or reach decisions in a new setting. Developing critical thinking ability has long been considered a key goal of higher education (King et al. 1990; Tsui 2002; van Gelder 2005; Davies \& Barnett 2015). Critical thinking is important for a country to have a properly skilled workforce (Andriusanitiene 2018; Howard et al, 2015; Igaune et al 2016). There is considerable research on the teaching methodologies for achieving this, as a very recent meta-analysis demonstrates (Abrami et al. 2015). However, there is less work on differential characteristics impacting critical thinking skills.

King et al. (1990) proposed that gender should be examined to determine if student characteristics have any impact on critical thinking skills. In their study, men scored somewhat better on critical thinking. Howard et al. (2015) were only able to cite a few prior studies, and the results were mixed. In their study, women improved on critical thinking measures from pre- to post-use of case-based modules, whilst men did not. 'Females and older students may take their academic work more seriously than their counterparts' (Howard et al., 2015, p. 142-143).

(C) 2020 Authors. This is an open-access article licensed under the Creative Commons Attribution-NonCommercial-NoDerivs License (http://creativecommons.org/licenses/by-nc-nd/3.0/) 
Various motivation aspects have received more attention in critical thinking studies (Howard et al., 2015); Bieliune (2018) focused on school culture as an effect on students' development. The effect of global culture in the development of critical thinking has been discussed (Normal et al., 2017). Al-Hunaiyyan et al. (2018) discussed how culture may hinder certain education methods. In this study, the authors took an approach that the overall society influences students.

Kuwait is a welfare state and heavily subsidises many segments of society. In particular, the government uses a large amount of resources on education. All Kuwait citizens (Kuwaitis) are eligible to receive monetary support whilst earning their first university degree. Kuwaitis earning an undergraduate degree will receive an increased monthly allowance from the government. Although the Kuwait government has policies in which citizens receive generous welfare benefits, these generous welfare benefits may reduce their motivation to achieve. As government spending on education increases, the future achievement of students may decrease (Falch \& Fischer, 2011).

Expatriates are people living in Kuwait who do not have Kuwait citizenship. Expatriate students do not receive government support in obtaining an undergraduate degree. In addition, Kuwait has various labour nationalisation policies that give employers incentives to have preferential hiring practices towards Kuwaitis over expatriates. Expatriate students may believe that they need to develop a higher level of business skills that will allow them to successfully compete for employment.

Student achievement has been identified as important to economic growth. In Kuwait, motivation to diversify the economy is important. One method of strengthening the economy has been through dedicating resources, so Kuwaiti citizens will progress in school.

Throughout the Arab World, high-level business executives tend to be somewhat dissatisfied with the ability of their educational systems to turn out graduates with the skills that Arab businesses need. In a recent survey sent to Chief Executive Officers (CEOs) in the region, just 32\% of the CEOs felt that the educational system provided graduates with adequate skills (Lootah \& Simon, 2009, p. 23). Amongst key skills, these CEOs look for 'analytical/critical skills' (91\%) and 'creative/innovative thinking' (90\%) whilst recruiting graduates, which are frequently cited (Lootah \& Simon, 2009, p. 27). One key recommendation for schools and curricula is to 'shift from memorization methods of appraisal to one that focuses on developing critical and analytical thinking skills' (Lootah \& Simon, 2009, p. 45). In the Gulf, business leaders are even less happy about the state of education than in other parts of the Arab World.

The Arab World CEOs in the Lootah and Simon (2009) survey think that private universities do a somewhat better job than State universities. Nevertheless, how to foster critical thinking is a key challenge in any classroom, private or state. Even when teaching methods are reformed, students must still be motivated to learn; obtaining student buy-in for developing critical thinking can be a difficult task in the rich Gulf States.

Kuwait is seeking to decrease its reliance on the production and sale of oil products. It is reported that $80 \%$ of the country's gross domestic product (GDP) is from oil. The workforce must have the skills to learn to adapt to these changes.

As Kuwait is a Muslim country, the laws and social customs promote a patriarchal family unit. Women are expected to devote their energies to the family over a job outside the home. Women are faced with social norms and policies that present more obstacles for their employment. Women may seek to develop stronger critical thinking skills in order to be competitive in obtaining a job.

The authors used a specific subsection about critical thinking skills, which is part of the Motivated Strategies for Learning Questionnaire (MSLQ). The subjects involved in this study comprised a convenience sample of 90 graduating seniors. The results showed that both characteristics, expatriate and female, are positively related to critical thinking skills. 


\section{Literature Review}

Kuwait is considered a welfare state in that the government is actively involved in the promotion of certain social programmes. In particular, the government is actively involved and spends large amounts of resources in the education sector. For children in kindergarten through high school, Kuwaiti children have access to free public education. The government has built schools and trained teachers. Every child has the opportunity for a free education through government support of free books, transportation and meals. The result is that Kuwait has one of the highest literacy rates in the Middle Eastern and North Africa (MENA) region: $94.4 \%$ for men and 91.0\% for women (Kuwait Defense \& Security Report Q4, 2010).

At the university level, Kuwait University (KU) was created to provide quality post-secondary education at low cost. The government provides funds for buildings and for teacher salaries and training. The government also heavily subsidises student tuition and books and provides a monthly living allowance. However, KU does not have the capacity to provide schooling for all Kuwaiti high-school graduates. To supplement demand for post-secondary education, several private universities have been formed within Kuwait. These universities are privately owned and profit oriented. Kuwaiti students who attend these private universities receive government assistance in the form of scholarships and a monthly living allowance. Thus, education for Kuwait citizens is heavily subsidised.

Falch and Fischer (2011) investigated the relationship between the welfare state and student performance. They developed several models that indicated that increased government intervention leads to reduced student achievement in future periods. In Kuwait, this issue would mainly affect students who are citizens.

Expatriate students do not receive support to attend school. Whilst a few scholarships exist for these students, tuition and books are primarily purchased using private funds. The performance of expatriate students may not be affected by the welfare rents of the Kuwait government. Expatriates were used as a comparison group because they would be less influenced by government subsidies.

Expatriate students were also considered to be a good comparison group because they may have a higher focus on acquiring skills that lead to higher probability of obtaining employment. The Kuwait government guarantees employment of its citizens. If a Kuwaiti cannot find employment in the private sector, a position in the government sector is provided. The Kuwait government encourages 'nationalisation' of the private sector by requiring businesses to have a minimum percentage of Kuwait citizens on the payroll. In addition, businesses receive government payments for each Kuwaiti who is employed. Expatriates do not have the advantage of employment in the government sector, and although a percentage of government employees are expatriates, the government's current goal is to reduce the number of expatriates working in the government sector. In the private sector, the government does not motivate employers to hire expatriates through the use of subsidies or hiring quotas. Expatriates may need better business skills in order to obtain employment.

Women are another group who may believe that they need higher credentials in order to obtain employment. An informal societal system may exist, which acts as a deterrent for the employment of women (Amaney, 2005). Kuwait is a Muslim country whose laws and social customs are based on local interpretations of the Quran and on associated religious beliefs. 'Family is the foundation of social life' in Arab society (Farsoun, 2004). Women maintain the family structure subordinate to male authority. According to custom, a woman's primary attention should be to the family unit and not to outside achievements, such as employment. Employers may have an informal policy to hire men instead of women. Thus, men have a competitive edge for jobs, and women may seek stronger job skills to overcome societal obstacles.

Workers in the business environment must have the ability to use knowledge in creative and innovative ways in order to adapt to changes. As critical thinking is such a highly desired business skill, potential employees may cultivate critical thinking strategies whilst in the university setting. In particular, those students who perceive that they are at an otherwise disadvantage (e.g. expatriates and women) may try to develop stronger critical thinking skills. 
Therefore, the first hypothesis is a comparison of students who are citizens of Kuwait to expatriate students.

$H_{1}$ : Critical thinking skills will be more highly developed for expatriates than for students who are Kuwait citizens.

Next hypothesis assumes that women are developing better critical thinking skills than men in order to be more competitive in the workforce.

$\mathrm{H}_{2}$ : Critical thinking skills will be more highly developed for women than for men.

\section{Methodology}

\section{The Questionnaire}

The questionnaire in this study used questions from the MSLQ to measure critical thinking. The MSLQ was developed in the United States by Paul Pintrich (Duncan \& McKeachie, 2005; Pintrich, Smith, Garcia \& McKeachie, 1991) and measures both motivations for learning and strategies used in learning by students. The entire MSLQ was used as part of a larger project than is reported here, but the following discussion focuses only on critical thinking. Critical thinking is considered one of the cognitive learning strategies that students use, and it 'refers to the degree to which student report applying previous knowledge to new situations in order to solve problems, reach decisions, or make critical evaluations' (Pintrich et al., 1991, p. 22).

The scale has been tested extensively and generally performs well. A recent review cited 58 uses of the critical thinking component, with a mean and median reliability of .78 and .80 , respectively. There was only one extreme outlier amongst these studies (i.e. a very low reliability for the critical thinking items), and eliminating it from the analysis resulted in a mean reliability of .79 (Taylor, 2012, p. 102-104).

Although developed and mostly tested in the United States, MSLQ has been used to investigate students' motivational orientations and their use of different learning strategies in some studies outside the United States. Taylor (2012) included 14 such studies (without noting specifically what the non-US countries are) in the sample of 56 studies that cover critical thinking. On a few of the MSLQ concepts, mean reliabilities outside the United States are significantly lower. However, most MSLQ concepts, including critical thinking, do have reliabilities on data from outside the United States that are very close to those inside the United States. On critical thinking, the mean reliability outside is .78, compared to .80 for studies in the United States. Although Taylor (2012) did not note where the non-US studies are located, she did note a slight reduction in the reliability for the critical thinking measure when it includes higher percentage of Asian respondents. MSLQ has been used in non-Western cultures occasionally, for example, in China, where a reliability of .76 was reported for critical thinking (Huang, 2008). MSLQ has also been used successfully in Malaysia (Yusri, 2010) and Turkey (Buyukozturk, Akgun, Ozkahveci \& Demirel, 2004).

At Kuwait University, the MSLQ was used to investigate the interactive relationship between students' motivation and cognition amongst students in a College of Education (Al-Ansari, 2005). Students who were able to regulate their efforts and attention made better grades. Students who reported a variety of metacognitive strategies did better on all performance measures. Students who stated that they were highly motivated for challenge and mastery performed at a higher level. However, this study did not include a few of the concepts on MSLQ; notably, critical thinking was not investigated. It does seem that measures of concepts in MSLQ generally have quite good reliability, including critical thinking and outside the context of the United States. Thus, we used the five questions presented in Table 1 to assess critical thinking. 
Table 1. Critical thinking questionnaire items taken from MSLQ

38. I often find myself questioning things I hear or read in this course to decide if I find them convincing.
47. $\quad$ When a theory, interpretation, or conclusion is presented in class or in the readings, I try to decide if there is
good supporting evidence.
51. I treat the course material as a starting point and try to develop my own ideas about it.
$66 . \quad$ I try to play around with ideas of my own related to what I am learning in this course.
$71 . \quad$ Whenever I read or hear an assertion or conclusion in this class, I think about possible alternatives.

The MSLQ was administered in English, because the curriculum at the university where the sample was taken was taught wholly in English. The students had mostly learned English as a second language with Arabic as their first language. (The majority of expatriates in this study are from other Arab countries, whereas citizens are from Kuwait.) The students had all met the minimum undergraduate entry-level requirement of TOEFL (Test of English as a Foreign Language) 520 or IELTS (International English Language Testing System) 5.5 to be admitted to the university and, at the time of this study, were in their fourth year. Taylor's (2012) review included only eight studies in which MSLQ was administered in languages other than English, but the mean reliability (and standard deviation of the reliabilities) for critical thinking was very close to the mean for English language administration (.77 vs. .80, respectively). A few studies compared both in a single study, showing that MSLQ in the native language gives consistent results compared to giving it in English to respondents who are competent in English as their second language. For example, similar results were obtained between English and Mandarin Chinese versions (Huang, 2008) and between English and Turkish versions (Buyukozturk et al., 2004).

In terms of number of scale points, only a few studies used fewer than the original seven-point scale, but here, the discrepancy was slightly greater for critical thinking, with reliabilities of .73 versus .80 for scales with five or fewer points versus seven points, respectively (Taylor, 2012, p. 113). In addition, most other concepts on MSLQ also gave slightly better reliabilities using a seven-point scale. This study used the original seven-point scale, ranging from $1=$ 'not at all true of me' to $7=$ 'very true of me', as in the original MSLQ (Pintrich et. al.., 1991).

\section{The Sample}

The sample for this pilot study comprised a convenience sample of 144 undergraduates. Amongst these, 91 of them were enrolled in the Fall Semester of 2010 in 4 sections of an auditing capstone course at the American University of Kuwait (AUK). The auditing capstone course in which the data were collected is a senior-level course taught in the Division of Business and Economics. The course's primary focus is to provide students with an understanding of the processes necessary to achieve audit objectives. It is a required course for all accounting majors in the division. The other 53 observations were collected in Spring 2014. This replication was performed to assess whether there might be any differences from the earlier semester. None were expected, but AUK is a relatively new school, and there could potentially have been some impact from programme changes. However, no differences were detected, so the data were combined, and the results from these combined data were used here.

Thus, amongst accounting majors, there was essentially no self-selection (because nearly all students answered the questionnaire), although there is no guarantee that students in other majors would have exactly the same pattern of responses.

The MSLQ was administered on the first day of class before any orientation to the course or before any academic expectations for the course were presented. Students in all sections of the course who were present on the day that the data were gathered could participate, and before administering the instrument, they were invited to participate if they wished. They were assured that their responses would be aggregated, thus ensuring their anonymity. Only one student out of the four sections opted not to participate. Students signed 
the informed consent form and were instructed to answer each of the 81 items on the instrument, as well as several demographic questions at the end.

The sample was nearly equally split between men and women (in both years); three respondents did not report gender, so there were 69 women and 72 men, and the proportions did not differ by year. About $71 \%$ of the respondents were Kuwaiti citizens. By year, slightly fewer in 2014 were Kuwaiti, but the difference was not significant. For the most part, the sample consisted of traditional students rather than older learners, with $92 \%$ aged 24 years or younger. Few were at the lower age categories of traditional students, as would be expected in an upper division course. The cumulative GPA ranged from 1.93 to 3.94, with a mean of 3.04. Eighty-eight per cent were taking a standard full-time course load of between 12 and 18 credits.

\section{Research Results}

\section{Descriptive Statistics}

Descriptive statistics showed that the mean scores on the critical thinking items were all significantly above the midpoint at four, ranging between 4.74 and 5.01 (Table 2). This finding indicated mild agreement on all of them that they are 'very true of me'.

Reliability of the concepts on the questionnaire compared favourably with the Cronbach alpha scores summarised in Taylor's (2012) review. Most reliabilities on the 15 concepts represented in MSLQ had values greater than .70 in our data, often considered the cut-off point for acceptable reliability (e.g. Trobia, 2008). The four MSLQ concepts with poor alpha in this sample (alpha < .7) were all amongst the six concepts that had weak reliability (alpha < .7) in the original MSLQ (Pintrich et al., 1991). Taylor's (2012) review showed that they are consistently somewhat weak across studies using MSLQ, with both mean and median alpha <.7. The MSLQ seemed to perform well in this Kuwaiti context.

The critical thinking subdimension in the original MSLQ manual had an alpha $=.80$ (Pintrich et al., 1991). Taylor's (2012) meta-analysis reported only one extreme outlier in 58 studies using the critical thinking subscale in MSLQ with median alpha $=.80$ and mean alpha $=.78$. Our data showed that critical thinking had an alpha $=.732$. The item-by-item statistics showed that the Cronbach alpha score would not be improved by deleting any individual item (Table 2). This compares well with other studies using this scale.

Table 2. Summary statistics for critical thinking items

\begin{tabular}{|l|cc|cc|}
\hline \multicolumn{1}{|c|}{ Question } & Mean & $\begin{array}{c}\text { Standard } \\
\text { deviation }\end{array}$ & $\begin{array}{l}\text { Corrected item- Cronbach's Alpha } \\
\text { total correlation }\end{array}$ \\
if item deleted
\end{tabular}

Note: see Table 1 for exact question wording; the 'listwise valid n' $=140$, because of a few cases of missing data.

\section{Factor Analysis}

Factor analysis was performed on the five critical thinking items to confirm that they are internally consistent. Trobia (2008), for example, noted that even a set of measures with high Cronbach alpha may still have subdimensions. In this case, a single eigenvalue was greater than 1.0, suggesting a single factor if this criterion is used alone. All five items load moderately well on the single factor, but the communalities on several of them are low, and the single factor accounts for only about half of variance (Table 3 ). 
Table 3. Factor analysis results for critical thinking, single factor

\begin{tabular}{|c|c|c|}
\hline Question & Factor 1 & Communalities \\
\hline Q38 question material to see if convincing & .625 & .391 \\
\hline Q47 decide if there is good supporting evidence & .632 & .400 \\
\hline Q51 develop my own ideas about material & .757 & .574 \\
\hline Q66 play around with ideas of my own regarding the material & .760 & .578 \\
\hline Q71 think about possible alternative explanations & .687 & .472 \\
\hline$\lambda($ Eigenvalue $)$ & 2.414 & \\
\hline Per cent of variance accounted for & 48.28 & \\
\hline
\end{tabular}

Note: Extraction method: Principal component analysis. One factor had $\lambda \geq 1$.

We also investigated a two-factor solution, because at .875, the second eigenvalue was somewhat close to 1.0 , the scree diagram was still descending sharply at the second factor, several communalities were low in the single factor solution, and the single factor accounted for only $50 \%$ of variance. These conditions suggest that the second factor may need to be included (Hair, Black, Babin \& Anderson, 2010). In the two-factor solution, the two different factors were easy to interpret, further supporting the use of two factors. This twofactor solution accounted for about two-thirds of variance, a much better result, and in the rotated solution, the two factors had similar weight (30-35\% of variance, each). The eigenvalues of four of the items were greatly improved. Factor 2 (Table 4) seems to be about critical appraisal of the material, and Factor 1 seems to be about using the material as a foundation to do one's own thinking about issues. Q71, thinking about possible alternative explanations, loads roughly similarly on both factors, indicating that it associates with both subdimensions. However, its communality is still slightly low.

Table 4. Factor analysis results for critical thinking, two factors

\begin{tabular}{|l|cc|c|}
\hline Question & Factor 1 & Factor 2 & Communalities \\
\hline Q38 question material to see if convincing & & .752 & .601 \\
Q47 decide if there is good supporting evidence & & .829 & .706 \\
Q51 develop my own ideas about material & .854 & .753 \\
Q66 play around with ideas of my own regarding the material & .856 & .757 \\
Q71 think about possible alternative explanations & .524 & .444 & .472 \\
\hline$\lambda$ (Eigenvalue) & 2.414 & .875 & \\
Per cent of variance accounted for in rotated solution & 35.817 & 29.971 & \\
Cumulative per cent of variance & 35.817 & 65.788 & \\
\hline
\end{tabular}

Notes: Factor loadings $<.4$ are not shown.

Extraction method: Principal component analysis.

Rotation method: Varimax with Kaiser normalisation. 
Given that there is still a substantial amount of variance outside the factors, whether we treat critical thinking as a single variable or as two sub-dimensions, we opted to do further analysis using factor score composite variables rather than a simple mean across the items. The factor scores collect the variance associated with the particular concept, but partition non-associated variance is left out.

\section{ANOVA}

Analysis of variance (ANOVA) was used to examine the impact of gender and citizenship on the composite variable represented in the single-factor solution for critical thinking. The key results are summarised in Table 5. The model is significant, and both gender and citizenship show significant impact on critical thinking (at 95\% confidence). The interaction between gender and citizenship is not significant. These two simple demographic variables account for nearly $10 \%$ of variance $(\mathrm{R}$-squared $=.069)$. Parameter estimates for the impact show that women use critical thinking more $(b=.508)$ than men and expats use critical thinking more $(b=.573)$ than citizens. Figure 1 represents this graphically; note that the interaction is not significant, so the seeming slight difference in slope on the two lines does not convey any meaning.

Table 5. ANOVA of gender and citizenship on critical thinking single factor score

\begin{tabular}{|l|cc|c|c|c|}
\hline Source & $\begin{array}{c}\text { Type III Sum of } \\
\text { Squares }\end{array}$ & df & Mean Square & F & Sig. \\
\hline Corrected model & 11.955 & 3 & 3.985 & 4.366 & .006 \\
Intercept & 1.625 & 1 & 1.625 & 1.781 & .184 \\
Gender & 3.951 & 1 & 3.951 & 4.328 & .039 \\
Citizenship & 5.401 & 1 & 5.401 & 5.917 & .016 \\
Gender * citizenship & .423 & 1 & .423 & .464 & .497 \\
\hline Error & 121.408 & 133 & .913 & & \\
Total & 133.415 & 137 & & & \\
Corrected total & 133.363 & 136 & & & \\
\hline
\end{tabular}

Note: Dependent variable: critical thinking single factor score.

R-squared $=.090$ (adjusted R-squared $=.069$ ).

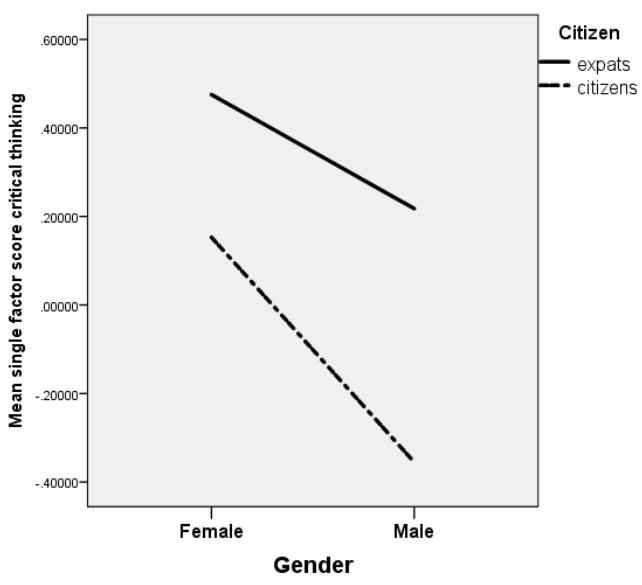

Fig. 1. Critical thinking single factor score, gender and citizenship effects 


\section{MANOVA}

MANOVA (multivariate analysis of variance) was used to analyse the impact of gender and citizenship on the two subdimensions. The multivariate tests showed that gender was significant $(p=.045)$, citizenship was significant $(\mathrm{p}=.050)$ but the interaction was not significant $(\mathrm{p}=.763)$. All four of the standard multivariate tests, Pillai's trace, Wilks' lambda, Hotelling's trace and Roy's largest root, showed exactly these same significances on each of these factors. Thus, we examined each subdimension, 'critical appraisal of the material' and 'use material as foundation to do own thinking'. The effects of gender and citizenship on the 'critical appraisal of the material' subdimension were not significant (Table 6a).

Table 6a. MANOVA of gender and citizenship on subdimension 2, 'critical appraisal of the material'

\begin{tabular}{|l|cc|c|c|c|}
\hline Source & Type III Sum of Squares & df & Mean Square & F & Sig. \\
\hline Corrected Model & 2.437 & 3 & .812 & .793 & .500 \\
Intercept & .312 & 1 & .312 & .305 & .582 \\
Gender & .070 & 1 & .070 & .069 & .794 \\
Citizenship & 1.486 & 1 & 1.486 & 1.450 & .231 \\
Gender * citizenship & .446 & 1 & .446 & .435 & .511 \\
\hline Error & 136.299 & 133 & 1.025 & & \\
Total & 138.737 & 137 & & & \\
Corrected total & 138.735 & 136 & & & \\
\hline
\end{tabular}

Note: Dependent variable: Subdimension 2 'critical appraisal of the material'; R-squared $=.018$ (adjusted R-squared $=.005)$.

However, the effects were significant on the subdimension 'use material as foundation to do own thinking'. Both gender and citizenship were significant (with p-values of .014 and .034, respectively), and the Rsquared value was .088, about the same as in the single factor case (Table 6b). The interaction between gender and citizenship was not significant. Parameter estimates for the impact were similar in size compared to the single factor case; they showed that women use critical thinking more $(\mathrm{b}=.510)$ than men, and expats use critical thinking more $(b=.443)$ than citizens. Figure 2 shows the effects graphically; note that it is much clearer in this graph that there is no interaction effect.

Table 6b. MANOVA of gender and citizenship on subdimension 1, 'use material as foundation to do own thinking'

\begin{tabular}{|l|cc|c|c|c|}
\hline Source & Type III Sum of Squares & df & Mean Square & F & Sig. \\
\hline Corrected model & 11.326 & 3 & 3.775 & 4.257 & .007 \\
Intercept & 1.421 & 1 & 1.421 & 1.602 & .208 \\
Gender & 5.559 & 1 & 5.559 & 6.268 & .014 \\
Citizenship & 4.029 & 1 & 4.029 & 4.542 & .035 \\
Gender * citizenship & .086 & 1 & .086 & .096 & .757 \\
\hline Error & 117.963 & 133 & .887 & & \\
Total & 129.355 & 137 & & & \\
Corrected total & 129.289 & 136 & & & \\
\hline
\end{tabular}

Note: Dependent variable: sub-dimension 1 'use material as foundation to do own thinking'; R-squared $=.088$ (adjusted R-squared $=.067$ ). 


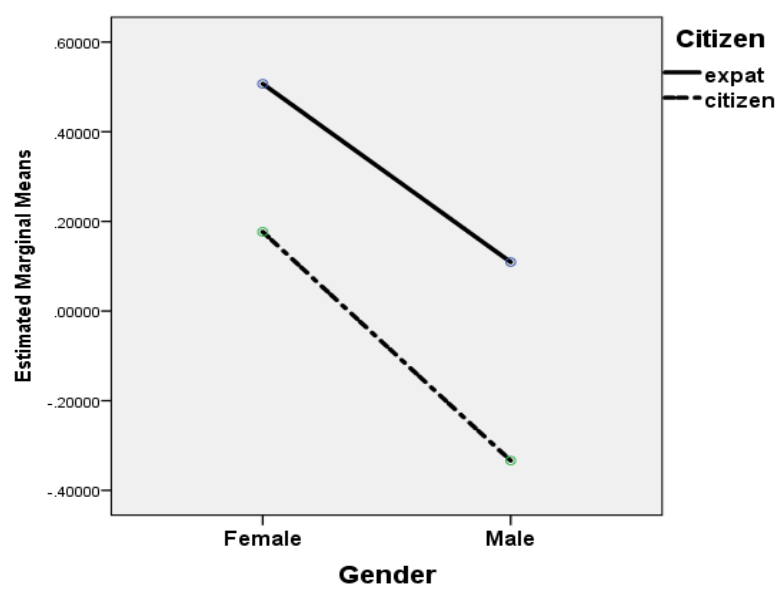

Fig. 2. Critical thinking subdimension 'use for own further thinking', gender and citizenship effects

\section{Conclusions}

The results support the hypotheses that student groups have different levels of critical thinking skills. Consistent with our expectations, we found that expatriate students had more highly developed critical thinking skills than students who were Kuwaiti citizens. We also found that women had more highly developed critical thinking skills than men. When comparing students across both citizenship and gender, Kuwaiti men tended to score the lowest in critical thinking skills, whereas expatriate women students tended to score the highest. We did not find any interaction amongst the various descriptors.

Thus, the welfare state measures undertaken by the government of Kuwait may be counter-productive. The guaranteed employment of its citizens and generous monetary support whilst in school may discourage the development of critical thinking skills. As previously mentioned, high-level business executives tend to be somewhat dissatisfied with the ability of the educational system to turn out graduates with the skills that Arab businesses need. To be consistent with governmental goals of improving the entire workforce, government policies and resources should be designed to enhance critical thinking skills in Kuwaitis with particular emphasis given to men.

Future research could focus on methods used to motivate particular groups (e.g. Kuwaiti men) to enhance their critical thinking skills. For example, critical thinking skills have been incorporated in Arabic language classes in public schools (Bahatheg 2019). A study delving into the effects of this approach might be useful. Also, Alhashem and Alkandari (2015) created a list of suggestions; the effect of any implementation of these suggestions would be interesting.

\section{References}

Abrami, P.C., Bernard, R.M., Borokhovski, E., Waddington, D.I., Wade, C.A., and Persson, T. 2015. Strategies for Teaching Students to Think Critically: A Meta-Analysis. Review of Educational Research, Vol. 85, No. 2, pp. 275314.

Alhashem, Fatima \& Ali Alkandari (2015) What Did Kuwait Learn from Its Participation in TIMSS Study? An Exploratory Case Study from Senior Supervisors’ Perspectives, Asian Social Science, 11(27), pp. 298310.

Al-Ansari, E. M. (2005) The Dynamic Interplay of Student Motivation and Cognition in the College of Education Students at Kuwait University, Social Behavior and Personality, 33(4), pp. 341-350. 
Al-Hunaiyyan, Ahmed, Rana A. Alhajri, \& Salah Al-Sharhan (2018) Perceptions and Challenges of Mobile Learning in Kuwait, Journal of King Saud University - Computer and Information Sciences, 30, pp. 279-289.

Al-Nakib, Rania (2015) Education and Democratic Development in Kuwait: Citizens in Waiting, Chatham House: The Royal Institute of International Affairs.

Amaney, J. (Winter 2005). Mosques, Collective Identity, and Gender Differences among Arab American Muslims, Journal of Middle East Women's Studies, 1(1), pp. 53-78.

Andriusaitiene, Daiva, (2018) Occupational Standards: A Key to Improving Match Between Skills and Lavour Market Needs in Lithuania, Journal of Economics and Culture, 15(2), pp. 88-98.

Bahatheg, Raja Omar (2019) Critical Thinking Skills in Elementary School Curricula in Some Arab Countries - A Comparative Analysis, International Education Studies, 12(4), pp. 217-235.

Bielieune, Simona. (2018) Culture as a Tool for School Improvement: The Case of Children's Socialization Centres, Journal of Economics and Culture, 15(1), pp. 70-77.

Buyukozturk, S., Akgun, O., Ozkahveci, O. \& Demirel, F. (2004) The Validity and Reliability Study of the Turkish Version of the Motivated Strategies for Learning Questionnaire, Educational Sciences: Theory \& Practice, 4(2), pp. 231-237.

Davies, M. \& Barnett, R. 2015. Introduction. In: The Palgrave Handbook of Critical Thinking in Higher Education (Davies, M. \& Barnett, R., eds.). Palgrave Macmillan, pp. 1-3.

Duncan, T. \& McKeachie, W. J. (2005) The Making of the Motivated Strategies for Learning Questionnaire, Educational Psychologist, 40(2), pp. 117-128.

Falch, Torberg \& Justina AV Fischer, "Welfare State Generosity and Student Performance: Evidence from International Student Tests", World Trade Institute, University of Bern, 2011.

Farsoun, S. K. "Culture and Customs of the Palestinians," Greenwood Press, 2004.

Hair, J. F., Black, W. C., Babin, B. J. \& Anderson, R. E. (2010) Multivariate data analysis (7th ed.). Englewood Cliffs, NJ: Prentice Hall.

Howard, L.W., Tang, T.L.-P., and Austin, M.J. 2015. Teaching critical thinking skills: Ability, motivation, intervention, and the Pygmalion effect. Journal of Business Ethics, Vol. 128, pp. 133-147.

Huang, S. (2008) Assessing Motivation and Learning Strategies using the Motivated Strategies for Learning Questionnaire in a Foreign Language Learning Context, Social Behavior and Personality, 36(4), pp. 529-534.

Igaune, Edite, Ilze Liepa-Balode, \& Agnese Hermane (2016) The Mutal Reciprocity of Education, Non-Formal Cultural Education and Social Capital, Journal of Economics \& Culture, 13(2), pp. 35-43.

King, P.M., Wood, P.K., and Mines, R.A. 1990. Critical Thinking among college and graduate students. Review of Higher Education, Vol. 13, No. 2, pp. 167-186.

Kuwait Defense \& Security Report Q4, Business Monitor International Ltd., 2010.

Lootah, Sultan \& A. Simon, "Arab Human Capital Challenge: The Voice of CEO's", Mohammed Bin Rashid AlMaktoun Foundation, 2009

Normal, Mario, Peral Chang, \& Leon Prieto (2017) Stimulating Critical Thinking in U.S. Business Students through the Inclusion of International Students, Journal of Business Diversity, 17(1), pp. 122-38.

Pintrich, P. R., Smith, D. A. F., Garcia, T. \& McKeachie, W. J. (1991) A Manual for the use of the Motivated Strategies for Learning Questionnaire (MSLQ), Ann Arbor: University of Michigan, National Center for Research to Improve Postsecondary Teaching and Learning.

Taylor, R. T. (2012) "Review of the Motivated Strategies for Learning Questionnaire (MSLQ) Using Reliability Generalization Techniques to Assess Scale Reliability". PhD dissertation, Auburn University (Alabama).

The Business Year (TBY). 2016. Kuwait 2016: Landmark Deals. VIP interview with Omar Alghanim, CEO of Alghanim Industries. https://www.thebusinessyear.com/kuwait-2016/landmark-deals/vip-interview (accessed 18 April 2016). 
Trobia, A. (2008) Cronbach's alpha. In: P.J. Lavrakas (Ed), Encyclopedia of Survey Research Methods. Thousand Oaks, CA: Sage, pp. 168-169.

Tsui, L. 2001. Fostering critical thinking through effective pedagogy: Evidence from four institutional case studies. The Journal of Higher Education, Vol. 73, No. 6, pp. 740-763.

van Gelder, T. 2005. Teaching critical thinking: Some lessons from cognitive science. College Teaching, Vol. 53, No. 1, pp. 41-46.

Yusri, G. (2010) Self-Regulated Learning Strategies Among Students of Arabic Language Course and Intensive Arabic Course in Mara University of Technology Malaysia, International Journal of Applied Educational Studies, 8(1), pp. 57-67. 